\title{
Investigating The Effect of DG Infeed on The Effective Cover of Distance Protection Scheme in Mixed-MV Distribution Network
}

\author{
Saad M. Saad ${ }^{a}$, Naser El Nailya, Faisal A. Mohamed ${ }^{\mathrm{b}}$ \\ ${ }^{a}$ College of Electrical and Electronics Technology-Benghazi, Benghazi, Libya \\ ${ }^{b}$ Authority of Natural Science Research and Technology, Tripoli, Libya,
}

\begin{abstract}
The environmental and economic features of renewable energy sources have made it possible to be integrated as Distributed Generation (DG) units in distribution networks and to be widely utilized in modern distribution systems. The intermittent nature of renewable energy sources, altering operational conditions, and the complex topology of active distribution networks makes the level of fault currents significantly variable. Thus, the use of distance protection scheme instead of conventional overcurrent schemes offers an appropriate alternative for protection of modern distribution networks. In this study, the effect of integrating multiple DG units on the effective cover of distance protection schemes and the coordination between various relays in the network was studied and investigated in radiology and meshed operational topologies. Also, in cases of islanded and grid-connected modes. An adaptive distance scheme has been proposed for adequate planning of protection schemes to protect complex networks with multiple distribution sources. The simplified simulated network implemented in NEPLAN represents a benchmark IEC microgrid. The comprehensive results show an effective protection measure for secured microgrid operation.
\end{abstract}

Keywords: Distance protection, distributed generation, distribution system, radial network, ring-type network.

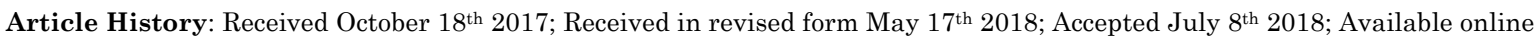

How to Cite This Article: Saad, S.M., Naily, N.E. and Mohamed, F.A. (2018). Investigating the Effect of DG Infeed on the Effective Cover of Distance Protection Scheme in Mixed-MV Distribution Network. International Journal of Renewable Energy Development, 7(3), 223-231. https://doi.org/10.14710/ijred.7.3.223-231

\section{Introduction}

The protection system plays an essential role in preserving reliable operation for the electric grid. The proper and accurate planning of the protection schemes is highly demanded to ensure the speed, selectivity, and reliability of protective relays to isolate the faulted parts from the rest of the network.

The over-current scheme is one of the most commonly used schemes in the DN due to their efficiency, simplicity and economical installation and implementation (Lasseter et al. 2011). However, the continuous transition of DNs in modern grids from their traditional radial arrangement to meshed and more complex arrangements, as a result of the continuous integration of DG, create small self-poweredcontrollable communities termed as a microgrid (Zeineldin et al. 2015).

DNs which operate in microgrid mode provide more efficient and economical sources of generation close to the remote loading communities and thus ensure the continuity of electricity feeding for critical and local loads in events of main grid failure. Microgrids improve the overall grid efficiency and the economic dispatch in the network. In addition, microgrid excessive generation provides a source of recovery for the network in cases of main grid failure and decrease the frequency and duration of outages. Such tremendous features asset the grid resilience to main source failures (Hooshyar et al. 2017).

Despite the aforementioned features of microgrids, the microgrid resilience might be jeopardized if the protection schemes are not properly planned and configured for faults within the microgrid boundaries (Memon et al. 2015). The utilization of conventional overcurrent scheme, which depends on the current measurement for fault detection, makes them unsuitable in diverse microgrid modes for several reasons (Hosseini et al. 2016). The most significant of which is the reliance of conventional OCR completely on the detected short circuit level since its rate is constantly changing according to the scale and the technology of the DGs used, and whether it operates in grid-connected mode or islanded mode (Che et al. 2014). Furthermore, the sharp distinction in fault levels among grid-connected modes and islanded modes since the main grid contribution for faults within the microgrid may be as large as times of small DGs within the microgrid (Khandare et al. 2017). Nowadays, the DNs are active in nature and formed in small self-controllable networks. Also, including various types of alternative energy sources with intermittent nature, which led to a

Corresponding author: jaruwan.t@eat.kmutnb.ac.th 
significant variation in the level of the short-circuit currents during different islanded and grid-connected modes (Saad et al. 2017). The considerable change in the short-circuit level in these different operational conditions burdens the operation and performance of overcurrent protection schemes in detecting various kind of faults in the network and make them even improbable to isolate (Sinclair et al. 2014). Utilization of distance Protection schemes could seem to be an appropriate alternative for protecting microgrids instead of conventional overcurrent schemes in cases of the weak faults nature. Since the distance scheme utilizes the impedance measurements instead of current to detect such faults in the network [Sharaf et al. 2015). All of these advantages and features of the distance protection scheme make it suitable for protecting microgrids. Thus, the implementation of distance protection makes it immune to high-impedance faults. The applicability of distance protection scheme could be increased by installing more distance relays in the microgrid and application of pilot protection schemes such as directional comparison blocking, utilizing relatively inexpensive power line carrier (PLC) protection (IEEE Standards Association 2011). The weak fault current nature of alternative energy sources and their frequent interconnection might affect the applicability of the overall configuration of distance protection scheme, despite the addition of more communication-assisted relays (Sinclair et al. 2014).

\section{Related Work}

Distribution systems are now being remodeled since active networks have been established in place of traditional passive networks (IEEE Standards Association et al. 2011). Therefore, propose new concepts and configuration that differ from conventional distribution systems. The author in (Zeineldin et al. 2006) suggest a voltagedependent scheme using reference frames for DG's voltage. (Nikkhajoei et al. 2006) is proposing the use of the current protection scheme to protect the network and to identify faults in the islanded mode. The differential scheme is also more commonly used in microgrid protection (Sortomme et al. 2010). The application of a differential diagram to protect the Distributed Power Generation (DPG) in grid and island situations (Kar et al. 2017). The number of problems facing differential diagrams in case of faults is overcome by the addition of high resistance in the rearrangement and the configuration of the protection scheme. Differential characteristics were also derived by separate Fourier transform approach. The examination of the constraints facing the infrastructure of differential schemes also illustrated in (Sortomme et al. 2013).

An adaptive plan for microgrid protection was also proposed for large penetration scenarios in grid-connected mode only (Brahma et al. 2004). In (Mahat et al. 2011) authors proposed a more simplistic scheme in cases of microgrid grid-connected and islanded modes. The author in (Hsieh et al. 2014) also proposed an adaptive protection scheme for induction generator wind turbines. The author in (Coffele et al. 2015) suggested adjusting the protection schemes configuration based on the penetration level and the change in the network topology. Studies in (Deng et al. 2015, El Naily et al. 2017, Najy et al. 2013) have tested and investigated the adaptability and flexibility of adaptive protection schemes with various microgrid topologies. The author in (Moirangthem et al. 2011) proposed a fault current limiter with a pre-calculated setting incorporated with overcurrent protection scheme to overcome the impact of the synchronous machine. In (Kar et al. 2016) a discrete differential evolution approach was proposed to enhance the microgrid protection in gridconnected mode only. In (TSIMTSIOS et al. 2018) the authors proposed a novel technique for planning the directional overcurrent protection scheme and tested the influence of different DG types with different capacities on the performance of microgrid protection. Despite all research highlighting the reliability and security of microgrid protection, the topic yet still need more feasibility and investigations.

Many other researchers propose extending out the distance relay reach in the distribution network with the distributed generation, as well as applying the distance protection scheme in a mixed distribution network with DG (Nikolaidis et al. 2018). The author has investigated the aspect of DG contribution and the deviation in resistance measurement in radial distribution feeders with DG.

\section{Proposed Distance Relays Coordination Strategy}

The weak nature of fault currents from inverter-based DGs, especially in islanded mode, reduce the sensitivity of overcurrent relays for high impedance faults (HIF) and could, even more, deteriorate the coordination between over-current relays in DN. The intermittent nature of Renewable Energy Sources (RESs) has significantly varied the fault current level in $\mathrm{DN}$, and make it difficult to detect HIF in the microgrid. All of these challenges necessitate the placement of distance scheme as an appropriate alternative for schemes based on current magnitude measurement in an active distribution network nature. Since the distance protection scheme does not significantly affect by the dispersed nature of RES and the decline in the fault current in the islanded mode (Sinclair et al. 2014). For the aforementioned features, distance scheme is being more desirable in active distribution networks (El Naily et al. 2018). Variations in tapped loads and the infeed and outfeed currents of DG may cause excessive over and underreach of distance relays. All the before-mentioned problems can be overcome by installing more distance relays in the microgrid and application of pilot protection schemes such as directional comparison blocking and utilizing a relatively inexpensive power line carrier (PLC) protection. Consequently, the DG fault nature can lead to an inappropriate applicability of distance relays in the microgrid, despite the addition of more relays linked through PLC. The following explanation will describe the unpropitious impact of inverter-based DGs.

\section{Proposed Distance Relays Coordination Strategy}

The study investigates and illustrates the procedures that should be tracked to get the accurate configuration of the distance scheme to mitigate the impact of penetrating multiple DG units. Design and planning the distance relay 
settings is a well-defined process, to produce the patterns are accurately employed, but the actual implementation will vary, depending not only on each relay characteristics but also on each type of relay.

\subsection{Characteristic of Distance protection}

Distance protection depends on the tolerance of the fault impedance measurement in front of the relay to the position of the fault to detect fault occurrence. Hence from fault impedance value, the possibility of a distance relay take place to decide whether the fault within the protected area by the relay. According to Fig. 2, Equation. 1 will be:

$$
Z_{m}=V_{m} / I_{m}
$$

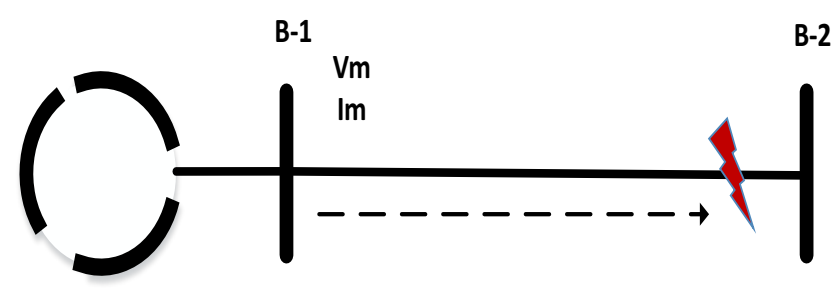

Fig. 1 The schematic diagram of distance protection

In normal operation, the distance relay measures an impedance of $\mathrm{Zm}$, which is approximately equivalent to the impedance of the load, since the impedance of the line $\mathrm{Zl}$ is very small comparing to $\mathrm{Zm}$. When a fault occurs in the protected zone the impedance is usually less than the impedance of the transmission line. If the measured impedance value is less than the set value, it indicates a fault within the relay protection zone.

\subsection{Setting distance protections for power line}

The planning of the distance protection scheme is based on dividing the protection zone into three protection zones with different tripping time. The first is the primary protection zone. The following two areas provide backup protection if the downstream relays do not operate as scheduled. Figure 3 illustrates these areas. Oftentimes, the startup characteristic and the operational reverse zone can be employed optionally to overreach the bus-bar zone.

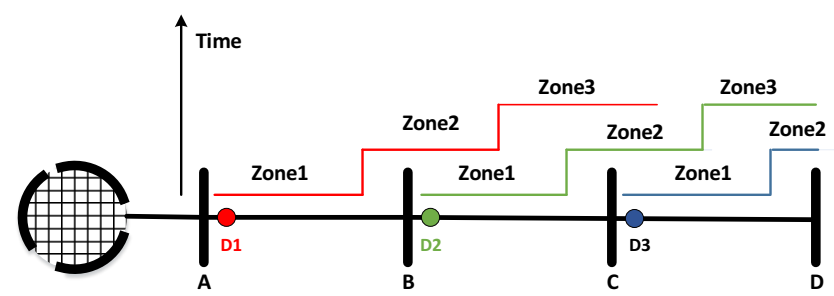

Fig. 2 Three-Grading Plan of Distance Protection on

Series of Lines

Numerical distance relays at the distribution substations provide the possibility of adjusting the protection zone setting for each relay according to the operational conditions. In this study, the first stage is restrained at $80 \%$ of the length of line B. The tripping time of this stage is usually the least possible since it is the main protection for this line as follow:

$$
Z_{1 A}=0.8 Z_{A B}
$$

In equation (3), the second backup phase of the distance protection is set to a higher tripping time than the first primary phase to ensure optimum coordination between the primary and backup relays and give sufficient time for the primary protective relay. Usually, the tripping time for the second stage is 0.4 seconds.

$$
\mathrm{Z}_{2 \mathrm{~A}}=0.8\left(\mathrm{Z}_{\mathrm{AB}}+0.8 \mathrm{Z}_{\mathrm{BC}}\right)
$$

The tripping time of the second stage is higher than the tripping time of the first stage with sufficient margin of 0.3-0.5 seconds to allow the primary relay and switchgear to isolate the fault first and reduce the isolated sections from the network. The third stage with the same philosophy is set for a tripping time of 0.7 seconds.

$$
\mathrm{Z}_{3 \mathrm{~A}}=0.8\left[\mathrm{Z}_{\mathrm{AB}}+0.8\left(\mathrm{Z}_{\mathrm{BC}}+0.8 \mathrm{Z}_{\mathrm{CD}}\right)\right]
$$

When renewable sources of energy are integrated into the DN, they will provide sources of feeding for downstream faults in the network, especially, in radiology nature. In Figure 4, the DG will increase the fault current to an additional high level. Consequently, the impedance measured at the relay D1 at line B1 will change and exceed the measured value in cases where these sources are not connected. The value of this measured impedance can be calculated by equation 5 .

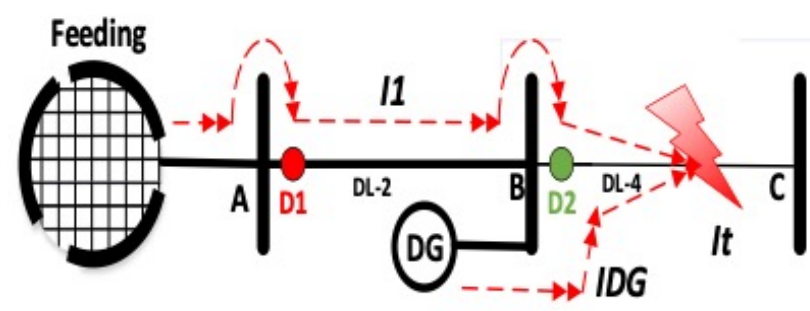

Fig. 3 Infeed current influence on the measuring impedance seen by $\mathrm{D} 1$

$$
Z_{m}=\frac{U_{m}}{I_{m}}=\frac{I_{1} Z_{D L-2}+I_{t} * Z_{k}}{I_{1}}
$$

The change in the measured impedance value in downstream and downstream relays as a result of intermittent renewable sources, if not taking into account, such a change in measured impedance will increase the impedance value and thus result in a non-selective tripping as in equation 3.

$$
k_{i f}=\frac{I_{t}}{I_{1}}=\frac{I_{1}+I_{D G}}{I_{1}}
$$

In DG connection situations, the $\mathrm{K}$ coefficient will equate and compensate for the change to retrieve the distance protection scheme setting. As a result, the equations of the three stages will be changed as follows (Gers et al. 2005):

$$
\begin{gathered}
\mathrm{Z}_{1 \mathrm{~A}}=0.8 \mathrm{Z}_{\mathrm{AB}} \\
\mathrm{Z}_{2 \mathrm{~A}}=0.8\left(\mathrm{Z}_{\mathrm{AB}}+0.8 \mathrm{Z}_{\mathrm{BC}} \_ \text {Kif }\right)
\end{gathered}
$$


Citation: Saad, S.M., Naily, N.E. and Mohamed, F.A.(2018). Investigating The Effect of DG Infeed on the Effective Cover of Distance Protection Scheme in Mixed-MV Distribution Network. Int. Journal of Renewable Energy Development, 7(3), 223-231, doi.org/10.14710/ijred.7.3.223-231

$\mathrm{P}$ a g e | 226

$$
\mathrm{Z}_{3 \mathrm{~A}}=0.8\left[\mathrm{Z}_{\mathrm{AB}}+0.8\left(\mathrm{Z}_{\mathrm{BC}}+0.8 \mathrm{Z}_{\mathrm{CD}}\right) \mathrm{Kif}\right]
$$

\subsection{Effective cover of relays}

In the interconnected systems which have multiple sources of supply, it may be counterproductive to have effective access to the distance relays measured by Ohm. It is possible can be estimated by calculating the ratio between several feed coefficients. Calculations for protection zones 2 , and 3 may be calculated with the following equations (Kar et al. 2017):

$$
\mathrm{Z}_{2}=\mathrm{Z}_{\mathrm{L} 1}+\left(1+\mathrm{K}_{1}\right) \mathrm{X}_{2} \mathrm{Z}_{\mathrm{L} 2}
$$

and

$$
\mathrm{Z}_{3}=\mathrm{Z}_{\mathrm{L} 1}+\left(1+\mathrm{K}_{2}\right) \mathrm{X}_{2} \mathrm{Z}_{\mathrm{L} 2}+\left(1+\mathrm{K}_{3}\right) \mathrm{X}_{3} \mathrm{Z}_{\mathrm{L} 3}
$$

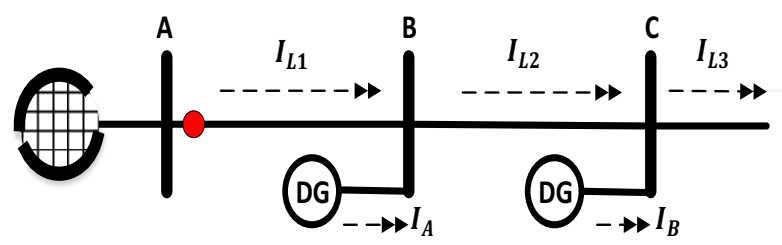

Fig. 4 Effect of an infeed on distance protection

\section{System Description}

Fig. 5 shows an IEC microgrid benchmark configuration connecting multiple DGs to investigate the reliability of the proposed methodology. The network implemented in NEPLAN Package (Neplan et al.).

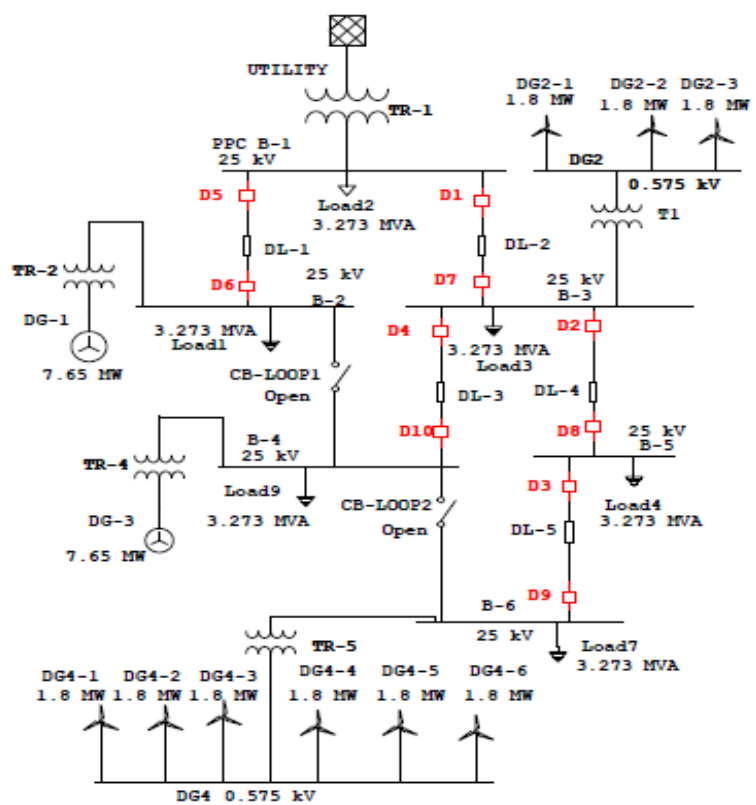

Fig. 5 IEC microgrid implemented in NEPLAN software

\section{Simulation and Results}

This study presents the influence of introducing multiple DGs on the reach of the distance protection scheme. The study proposes the strategy for an adaptive scheme to mitigate the encountered influence of the intermittent renewable energy sources. Fig. 6 shows a significant difference in fault currents between islanded and gridconnected modes. Also, in mesh and radial topology (connected through CB LOOP1 and CB LOOP2). In gridconnected mode, the fault current is higher than in islanded operational mode. This is due to the high short circuit level compared with the fault current of local DGs in the microgrid. Additional higher fault current in mesh topology mode compared with the radial topology has been noticed. This due to the effect of DGs in feeds in the microgrid. Also, the study investigates the change in connecting DG4 at bus 5 and its impact on Zone 3 and the possibility to resolve the problem of distance relay under reach by utilizing a proper adaptive scheme strategy.

In Table. 1, faults created at DL, DL2, DL3, and DL4 in case of primary protection fails. The faulted line may have one primary relay and one or more backup relays. Consider fault at bus-bar DL1 the fault occurs on bus-bar far from the main feeder. If the fault strike at Bus DL1. D5 and D6 should act as a primary relay to clear the fault at Bus DL1 and D7 as a back-up1 relay, and D8, D10 as a back-up2 relay. Simulation results are shown in Table. 2 in different operating modes with radial network topology.

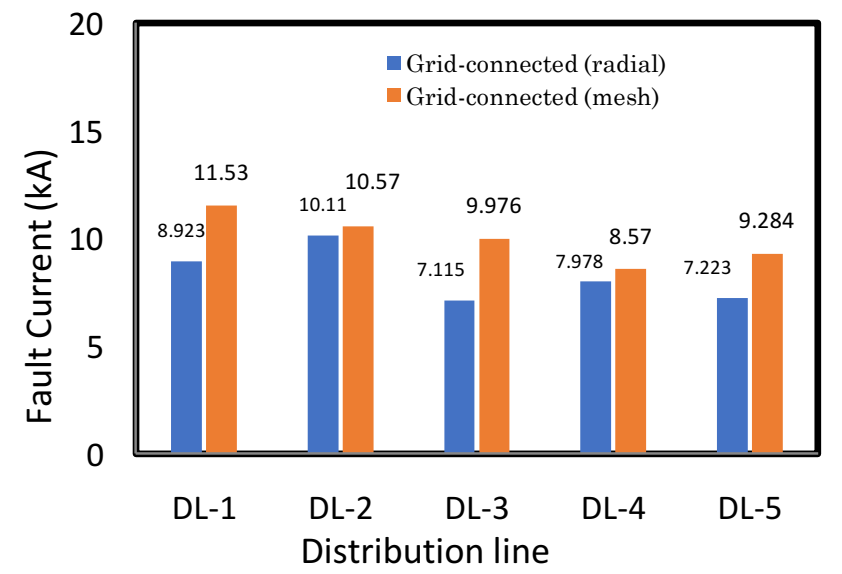

Fig. 6 Fault Currents in Grid-connected Mode

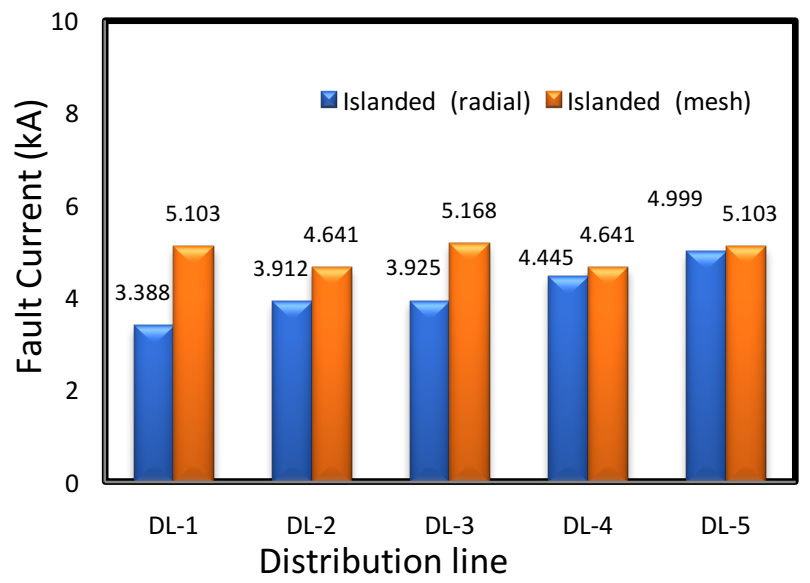

Fig. 7 Fault Currents in Islanded Mode

From the results, the response (dependability) of both relays (in both primary and backup protection) are slow in islanded mode compared to the grid-connected mode for radial topology. DL5 are investigated to achieve a reliable protection performance. Each primary protection relay must be equipped with a second line of 
protection (backup protection) to substantiate in case primary protection fails.

Table 1

The Primary and Backup Relay Pair in Grid Connected Mode with Mesh Topology

\begin{tabular}{|llll|}
\hline & $\begin{array}{l}\text { Primary } \\
\text { relay } \\
\text { Zone1 }\end{array}$ & $\begin{array}{l}\text { Backup1 } \\
\text { relays } \\
\text { Zone2 }\end{array}$ & $\begin{array}{l}\text { Backup2 } \\
\text { relays } \\
\text { Zone3 }\end{array}$ \\
\hline Fault in DL1 & D5 & D7 & D8, D10 \\
& D6 & D6 & \\
Fault in DL2 & D1 & D8, D10 & D9 \\
& D7 & D1 & \\
Fault in DL3 & D4 & D8 & D9 \\
& D10 & D10, D1 & D6 \\
Fault in DL4 & D2 & D9 & \\
& D8 & D2 & D1 \\
Fault in DL5 & D3 & & \\
& D9 & & \\
\hline
\end{tabular}

Consider a fault at bus-bar DL1 in case of fault occurs on bus-bar far from the main feeder. If the fault strike at Bus DL1, D5 and D6 should act as primary relays to clear the fault at Bus DL1, and D7 as a back-up1 relay, and D8, D10 as back-up 2 relays. The results are shown in Table 2 in different situations with radial network topology.

It is observed that performance (dependability) of the proposed relays (in both primary and backup protection) is slow in islanded mode compared to the gridconnected mode for radial topology.

From those results, under varying operating conditions, there will be wide variations in fault current seen by each relay. Relays placed at both ends of the lines must be selective and reliable as there is bidirectional power flow due to the presence of DGs in the microgrid. To sum up, the inherent directionality of distance relays performed as a measured negative impedance is used to cope with sympathetic tripping issues. Downstream power flow is established on due to DG small capacity, therefore the settings do not require tripping zones in the left-half plane of the R-X diagram.

In Tables $(3,4,5,6)$, in case of fault occurrence in a given line, the primary relay will trip after time $0.1 \mathrm{~s}$ in zone1. In cases of fault occurrence, primary relay Backup1 will trip after $0.4 \mathrm{~s}$ in zone 2 and if a fault occurs in Backup1, Backup2 will trip after $0.7 \mathrm{~s}$ in zone 3 . It is highlighted from the after mentioned tables that the proposed protection scheme ensures fault isolation in the expected time. Even though the current level changes significantly in the grid-connected and islanded modes. For example, when the fault level changes significantly at lines DL1 and DL3 in different operational modes. The tripping characteristics for different stages did not vary from the expected relay tripping time. The proposed scheme ensures at least two stages for each fault in the microgrid. Fig. 8 show the Tripping schedules of a threegrading plan for relays D1, D2, D3 in grid-connected modes (radial topology) which protecting Bus-bars B-1, B3 and B-5 respectively. The first stage of distance relay D1 protects the area between the two substations B1 and B2 and serves as a first backup stage for the area between the substations B3 and B5. Furthermore, operating as a second backup stage for the area between the substations B5 and B6.
The proposed planning scheme ensures reliability for the protection stages and overcoming overlap and nonselective tripping to be present, especially, in the meshed network topology. Fig. 9 shows the Tripping schedules of the three-grading plan for relays D9, D8, D7 in gridconnected modes (radial topology) which protecting Busbars B-6, B-5 and B-3 respectively. The coordination between the relays D9, D8, D7 ensure the selectivity since the only source of supply in case of a fault in line DL5 in the radial topology would be the utility main feeder.

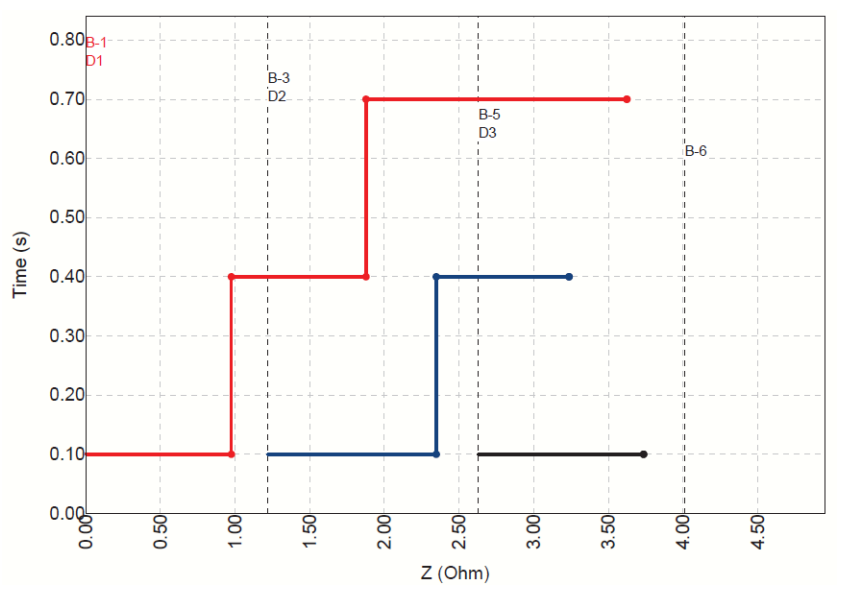

Fig. 8 Three-grading plan of distance protection on series of lines

The same strategy applied to provide reliability in case of a fault at line DL4. Fig. 10 show the Tripping schedules of a three-grading plan for relays D6, D1, D2 in islanded modes (radial topology) which protecting Bus-bars B-2, B1 and $\mathrm{B}-1$ respectively.

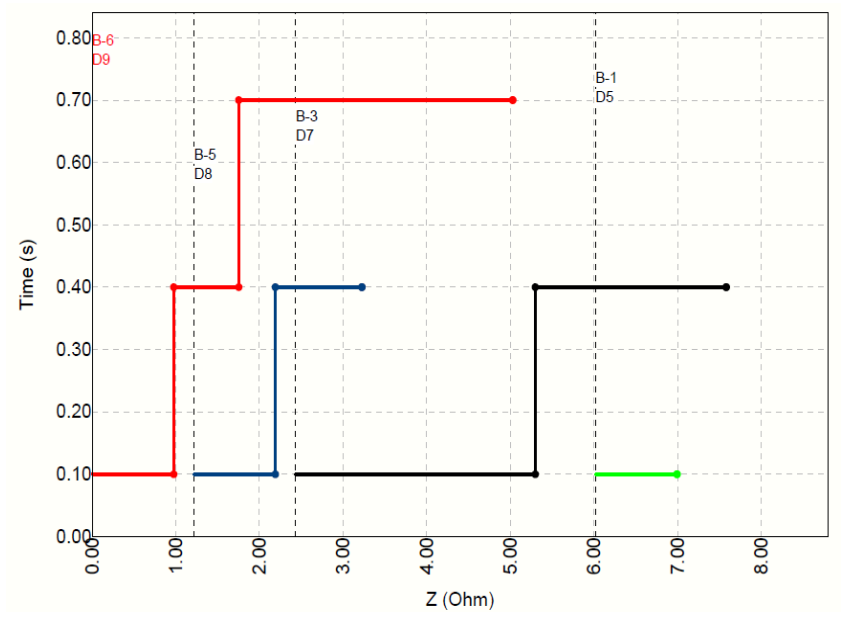

Fig. 9 Three-grading plan of distance protection on series of lines

Figures 11,12 shows the tripping characteristics for distance relay D1 in case of a fault at line DL4 and DL5 in a grid-connected mode when multiple DGs connected to the network. D1 operates in the second stage in case of a fault at DL4, and D1 and D2 as a third stage in case of a fault at DL5. Also, the figures showing the influence of fault incidence when it occurs at DL5 and DL4 on the tripping characteristics and weather D1 and D2 trip on the third and second stages or no 
Citation: Saad, S.M., Naily, N.E. and Mohamed, F.A.(2018). Investigating The Effect of DG Infeed on the Effective Cover of Distance Protection Scheme in Mixed-MV Distribution Network. Int. Journal of Renewable Energy Development, 7(3), 223-231, doi.org/10.14710/ijred.7.3.223-231

$\mathrm{P}$ a g e | 228

Table 2.

Relay group settings for 4 different network topologies

\begin{tabular}{|c|c|c|c|c|c|c|c|c|c|c|c|c|}
\hline & \multicolumn{3}{|c|}{$\begin{array}{c}\text { Group A } \\
\text { Grid connected-r }\end{array}$} & \multicolumn{3}{|c|}{$\begin{array}{c}\text { Group B } \\
\text { Grid connected-m }\end{array}$} & \multicolumn{3}{|c|}{$\begin{array}{l}\text { Group C } \\
\text { Islanded-r }\end{array}$} & \multicolumn{3}{|c|}{$\begin{array}{l}\text { Group D } \\
\text { Islanded-m }\end{array}$} \\
\hline & $\begin{array}{l}\text { Zone1 } \\
\mathrm{R}, \mathrm{X}\end{array}$ & $\begin{array}{l}\text { Zone } 2 \\
\mathrm{R}, \mathrm{X}\end{array}$ & $\begin{array}{l}\text { Zone } 3 \\
\mathrm{R}, \mathrm{X}\end{array}$ & $\begin{array}{c}\text { Zone } 1 \\
\mathrm{R}, \mathrm{X}\end{array}$ & $\begin{array}{c}\text { Zone } 2 \\
\mathrm{R}, \mathrm{X}\end{array}$ & $\begin{array}{c}\text { Zone } 3 \\
\mathrm{R}, \mathrm{X}\end{array}$ & $\begin{array}{l}\text { Zone } 1 \\
\mathrm{R}, \mathrm{X}\end{array}$ & $\begin{array}{l}\text { Zone } 2 \\
\mathrm{R}, \mathrm{X}\end{array}$ & $\begin{array}{l}\text { Zone } 3 \\
\mathrm{R}, \mathrm{X}\end{array}$ & $\begin{array}{l}\text { Zone } 1 \\
\mathrm{R}, \mathrm{X}\end{array}$ & $\begin{array}{l}\text { Zone } 2 \\
R, X\end{array}$ & $\begin{array}{l}\text { Zone } 3 \\
\mathrm{R}, \mathrm{X}\end{array}$ \\
\hline D1 & $\begin{array}{l}0.48 \\
1.64\end{array}$ & $\begin{array}{l}0.96 \\
, 3.16\end{array}$ & $\begin{array}{l}1.90 \\
6.26\end{array}$ & $\begin{array}{l}0.48 \\
1.64\end{array}$ & $\begin{array}{l}0.76 \\
2.57\end{array}$ & $\begin{array}{l}1.83 \\
6.03\end{array}$ & $\begin{array}{l}0.48 \\
1.64\end{array}$ & $\begin{array}{l}1.30 \\
4.38\end{array}$ & $\begin{array}{l}3.39 \\
12.94\end{array}$ & $\begin{array}{l}0.48 \\
1.64\end{array}$ & $\begin{array}{l}1.58 \\
5.32\end{array}$ & $3.03,10.31$ \\
\hline D2 & $\begin{array}{l}0.48 \\
1.64\end{array}$ & $\begin{array}{l}0.88 \\
2.95\end{array}$ & $\cdots--$ & $\begin{array}{l}0.48,1 \\
64\end{array}$ & $\begin{array}{l}0.88 \\
2.95\end{array}$ & $\begin{array}{l}1.56, \\
5.13\end{array}$ & $\begin{array}{l}0.48 \\
1.64\end{array}$ & $0.88,2.95$ & $\cdots-\cdot$ & $\begin{array}{l}0.48 \\
1.64\end{array}$ & $\begin{array}{l}0.88 \\
2.95\end{array}$ & $\cdots-\cdot$ \\
\hline D3 & $\begin{array}{l}0.48 \\
1.64\end{array}$ &.-- & $\cdots-\cdot$ & $\begin{array}{l}0.48 \\
1.64\end{array}$ &.---- & -.-.- & $\begin{array}{l}0.48, \\
1.64\end{array}$ & $\cdots-\cdot$ & $\cdots-\cdot$ & $\begin{array}{l}0.48, \\
1.64\end{array}$ & $-\cdot-.-$ & $\cdots-$ \\
\hline D4 & $\begin{array}{l}0.48,1 \\
64\end{array}$ & $-\cdots-\cdot$ & $-\cdots-\cdot$ & $\begin{array}{l}0.48 \\
1.64\end{array}$ & $-\cdots-\cdot$ & $\cdots$ & $\begin{array}{l}0.48 \\
1.64\end{array}$ & $\cdots-\cdot$ & $-\cdots-\cdot$ & $\begin{array}{l}0.48 \\
1.64\end{array}$ & $\cdots-\cdot-$ & $\cdots$ \\
\hline D5 & $\begin{array}{l}0.48 \\
1.64\end{array}$ & $\cdots-\cdot$ & $\cdots-\cdot$ & $\begin{array}{l}0.48 \\
1.64\end{array}$ & $\cdots-\cdot-$ & $\cdots$ & $\begin{array}{l}0.48 \\
1.64\end{array}$ & $\cdots$ & $\cdots-\cdot$ & $\begin{array}{l}0.48 \\
1.64\end{array}$ & $\cdots-\cdot$ & $\cdots-\cdot$ \\
\hline D6 & $\begin{array}{l}0.48,1 \\
64\end{array}$ & $\begin{array}{l}5.05 \\
15.89\end{array}$ & $\begin{array}{l}9.67 \\
30.40\end{array}$ & $\begin{array}{l}0.48 \\
1.64\end{array}$ & $\begin{array}{l}5.05 \\
15.89\end{array}$ & $\begin{array}{l}9.67 \\
30.4\end{array}$ & $\begin{array}{l}0.48 \\
1.64\end{array}$ & $0.88,2.95$ & $\begin{array}{l}1.53,5.1 \\
3\end{array}$ & $\begin{array}{l}0.48 \\
1.64\end{array}$ & $\begin{array}{l}0.88,2.9 \\
5\end{array}$ & $1.86,6.03$ \\
\hline D7 & $\begin{array}{l}0.48,1 \\
64\end{array}$ & $\begin{array}{l}2.52 \\
7.32\end{array}$ & $\cdots-\cdot-$ & $\begin{array}{l}0.48 \\
1.64\end{array}$ & $\begin{array}{l}0.88 \\
2.95\end{array}$ & $\cdots-$ & $\begin{array}{l}0.48 \\
1.64\end{array}$ & $\begin{array}{l}0.88 \\
2.95\end{array}$ & $\cdots-\cdot-$ & $\begin{array}{l}0.48 \\
1.64\end{array}$ & $\begin{array}{l}0.88 \\
2.95\end{array}$ & $\begin{array}{l}1.74 \\
10.69\end{array}$ \\
\hline D8 & $\begin{array}{l}0.48,1 \\
64\end{array}$ & $\begin{array}{l}1.04, \\
3.42\end{array}$ & $\cdots-\cdot$ & $\begin{array}{l}0.48 \\
1.64\end{array}$ & $\begin{array}{l}1.04, \\
3.42\end{array}$ & $-\cdots-\cdot$ & $\begin{array}{l}0.48 \\
1.64\end{array}$ & $1.04,3.42$ & $\begin{array}{l}2.98 \\
9.44\end{array}$ & $\begin{array}{l}0.48 \\
1.64\end{array}$ & $\begin{array}{l}1.34 \\
4.58\end{array}$ & $\begin{array}{l}2.44 \\
8.30\end{array}$ \\
\hline D9 & $\begin{array}{l}0.48,1 \\
64\end{array}$ & $\begin{array}{l}0.88 \\
2.95\end{array}$ & $\begin{array}{l}2.64 \\
8.46\end{array}$ & $\begin{array}{l}0.48 \\
1.64\end{array}$ & $\begin{array}{l}0.88 \\
2.95\end{array}$ & $\begin{array}{l}2.64 \\
8.46\end{array}$ & $\begin{array}{l}0.48 \\
1.64\end{array}$ & $0.88,2.95$ & $\begin{array}{l}3.86,11 . \\
81\end{array}$ & $\begin{array}{l}0.48 \\
1.64\end{array}$ & $\begin{array}{l}0.88 \\
2.95\end{array}$ & $3.29,10.72$ \\
\hline D10 & $\begin{array}{l}0.48,1 \\
64\end{array}$ & $\begin{array}{l}1.08, \\
6.60\end{array}$ & $\begin{array}{l}5, \\
21.29\end{array}$ & $\begin{array}{l}0.48, \\
1.64\end{array}$ & $\begin{array}{l}1.08, \\
3.60\end{array}$ & $\begin{array}{l}3.44 \\
12.38\end{array}$ & $\begin{array}{l}0.48, \\
1.64\end{array}$ & $\begin{array}{l}1.24, \\
4.16\end{array}$ & $\begin{array}{l}2.24,7.4 \\
8\end{array}$ & $\begin{array}{l}0.48, \\
1.64\end{array}$ & $\begin{array}{l}1.08, \\
3.60\end{array}$ & $1.92,6.39$ \\
\hline
\end{tabular}

Table 3

Relays Operating Times in Grid Connected- Islanded Topology

\begin{tabular}{lllllllllll}
\hline Islanded-r & D1 & D2 & D3 & D4 & D5 & D6 & D7 & D8 & D9 & D10 \\
\hline Fault in DL1 & & & & & 0.1 & 0.1 & 0.4 & 0.7 & 0.7 & 0.7 \\
Fault in DL2 & 0.1 & & & & & 0.4 & 0.1 & 0.4 & 0.7 & 0.4 \\
Fault in DL3 & 0.7 & & & 0.1 & & 0.4 & & 0.4 & 0.7 & 0.1 \\
Fault in DL4 & 0.7 & 0.01 & & & & 0.4 & & 0.1 & 0.7 & 0.4 \\
Fault in DL5 & & & 0.1 & & & 0.4 & & & 0.01 & 0.7 \\
\hline
\end{tabular}

Table 4

Relays Operating Times in Grid Connected- Meshed Topology

\begin{tabular}{lllllllllll} 
Grid connected-r & D1 & D2 & D3 & D4 & D5 & D6 & D7 & D8 & D9 & D10 \\
\hline Fault in DL1 & & & & & 0.1 & 0.1 & 0.4 & 0.7 & & 0.7 \\
Fault in DL2 & 0.1 & & & & & 0.4 & 0.1 & 0.4 & 0.7 & 0.4 \\
Fault in DL3 & 0.4 & & & 0.1 & & & & 0.4 & 0.7 & 0.1 \\
Fault in DL4 & 0.4 & 0.1 & & & & & & 0.1 & 0.7 & 0.7 \\
Fault in DL5 & 0.7 & & 0.1 & & & & & & 0.1 & 0.7 \\
\hline
\end{tabular}

Table 5

Relays Operating Times in Islanded Connected- Islanded Topology

\begin{tabular}{lllllllllll}
\hline Grid connected-m & D1 & D2 & D3 & D4 & D5 & D6 & D7 & D8 & D9 & D10 \\
\hline Fault in DL1 & & & & & 0.1 & 01 & & & & \\
Fault in DL2 & 0.1 & & & & & 0.4 & 0.1 & 0.4 & 0.7 & 0.4 \\
Fault in DL3 & 0.4 & & & 0.1 & & & & 0.7 & 0.7 & 0.01 \\
Fault in DL4 & 0.7 & 0.01 & & & & & & 0.1 & 0.7 & 0.4 \\
Fault in DL5 & 0.7 & & 0.1 & & & & & & 0.1 & \\
\hline
\end{tabular}

Table 6

Relays Operating Times in Islanded Connected- Meshed Topology

\begin{tabular}{lllllllllll}
\hline Islanded-r & D1 & D2 & D3 & D4 & D5 & D6 & D7 & D8 & D9 & D10 \\
\hline Fault in DL1 & & & & & 0.1 & 0.1 & 0.4 & 0.7 & 0.7 & 0.7 \\
Fault in DL2 & 0.1 & & & & & 0.4 & 0.1 & 0.4 & 0.7 & 0.4 \\
Fault in DL3 & 0.7 & & & 0.1 & & 0.4 & & 0.4 & 0.7 & 0.1 \\
Fault in DL4 & 0.7 & 0.01 & & & & 0.4 & & 0.1 & 0.7 & 0.4 \\
Fault in DL5 & & & 0.1 & & & 0.4 & & & 0.01 & 0.7 \\
\hline
\end{tabular}




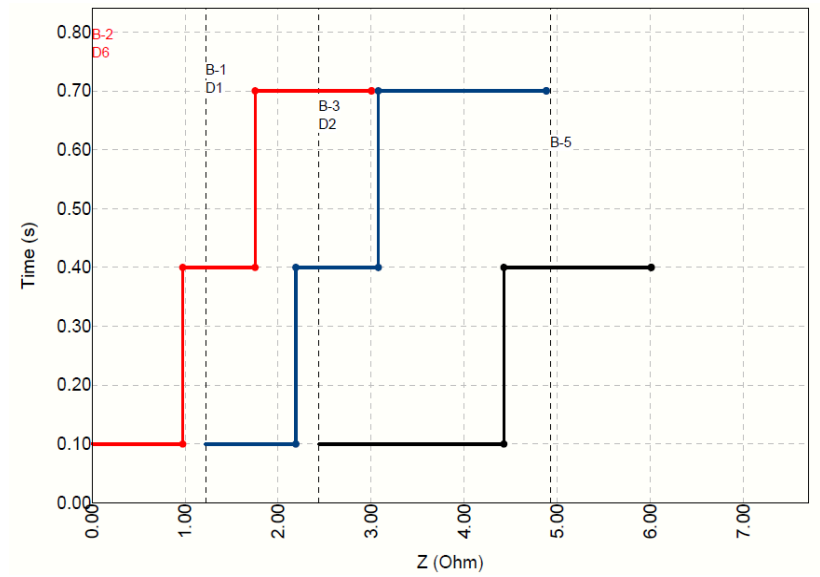

Fig. 10 Three-grading plan of distance protection on series of lines

Each stage in the distance relays in the microgrid has a directional characteristic to identify and detect forward faults downstream the relay.

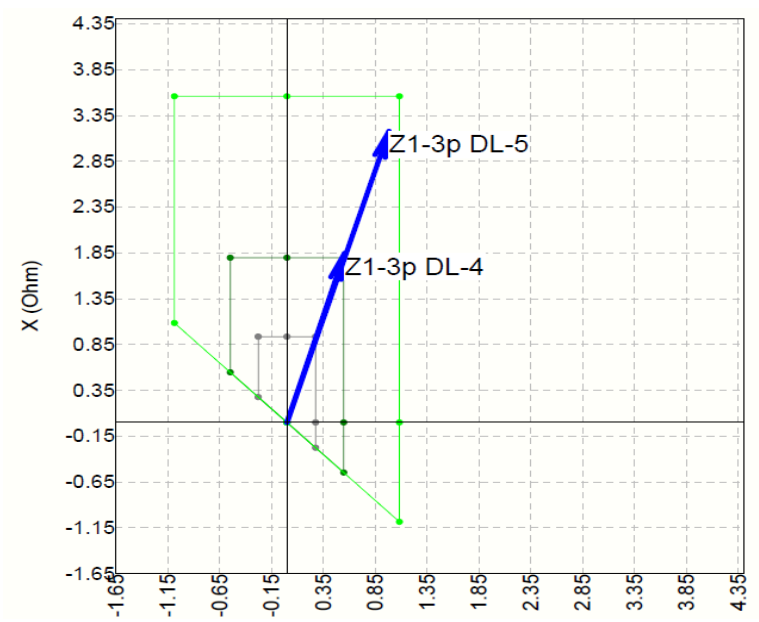

Fig. 11Tripping Characteristics of D1 with Fault in DL5

The distinction between $\mathrm{Zl}$ and $\mathrm{Zm}$ determine the definite tripping time for each fault incident and whether the relay trip or not. It is noted from Fig. 11 that the insertion of DG in the network affects the reach of the distance relay D1 in the second and third stage. The lines DL6 and DL5 impedance values when the distributed power source was incorporated were significantly changed, which in the case of large-share integration could lead to a under reach of the assigned distance relay.

Figure 12 also shows the effect of DGs entry in the second and third protective stages on the distance relay D6. In case of ground faults and high impedance faults, the function of distance relay D6 due to the integration of DG may affect the provision of backup protection for downstream relays D8 and D7 in case of faults on the lines DL4 and DL2 respectively.

\subsection{Effective Cover of Distance Relay}

What is meant to mean of the effective cover of distance relay is the region that the protection of distance relay compiles, either the primary protection zone or the second or third backup protection zones, as additional protection for the lines in front of the distance relay. The insertion and disconnection of DGs and the increasing penetration of such distributed resources, which is expected to increase dramatically, presents a dilemma for providing a comprehensive configuration strategy that provides optimal coordination between different distance relays in the future active networks.

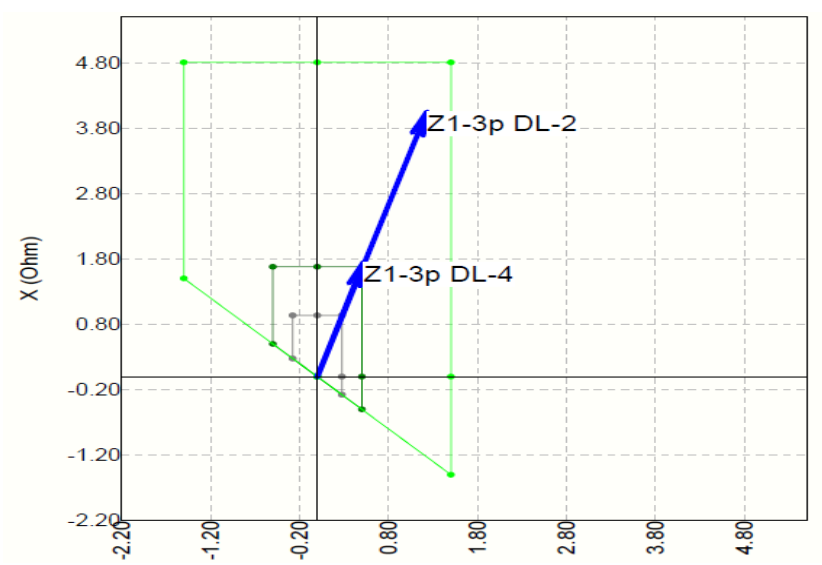

Fig. 12 Tripping Characteristics of D1 with Fault in DL5

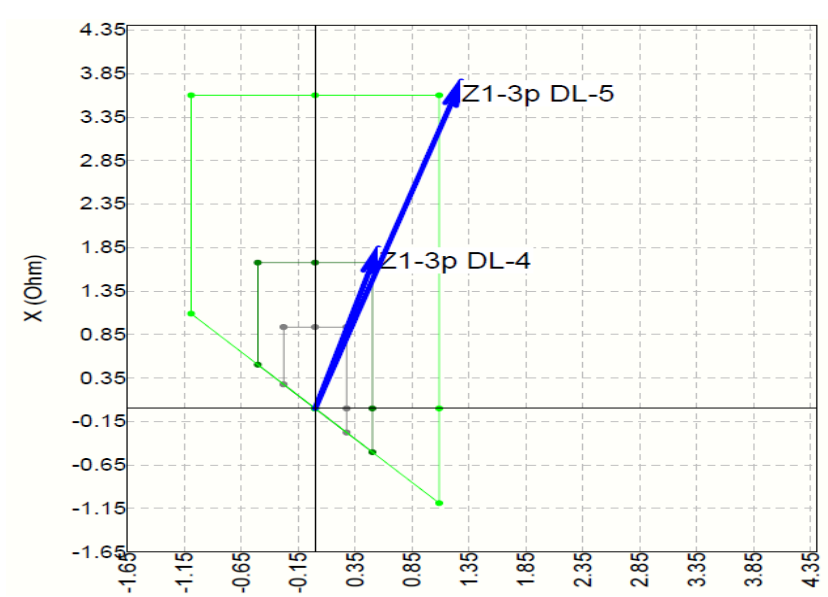

Fig. 13 Tripping Characteristics of D1 with Fault in DL5

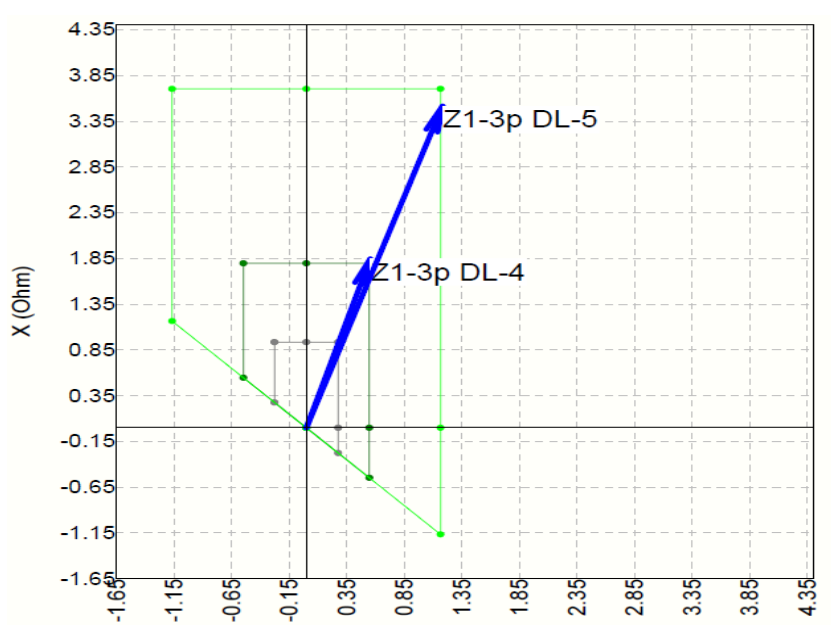

Fig. 14 Tripping Characteristics of D1 with Fault in DL4

The percentage of effective cover as defined in Section 4.3 is 50 percent and 25 percent respectively. However, in some cases, mainly due to the restrictions in the reach of the relays, it is not possible to set the calculated values of the second and third stages in the relay accurately. Therefore, a necessity to evaluate the effective cover 
provided by the relay over adjacent lines against the actual setting value is required.

With the use of these equations and with the appropriate infeed constants, it is possible to calculate the effective reach of the relay over any of the lines adjacent to the protected line. In figures. 13 when the position of DG4 is changed to be installed at bus 5 rather than bus 7 , it is observed that the operation of distance relay $\mathrm{D} 1$ for a fault at line DL4 will not trip in the expected configured time. D1 will see the fault outside the second protective stage, the impedance of fault seen by relay D1 will exceed the predefined value of the second stage and will trip as a fault in the third stage. This situation will delay the tripping time to 0.7 seconds. Figure 14 shows the later adjustment for D1 to consider the multiple insertions of DG. Figure. 14 shows the improvement in the performance in the operation of D1. D1 will see the fault impedance in the second stage and trip and isolate the fault at DL5 in the requisite stage of 0.4 seconds.

As indicated by the simulation results, the use of the infeed coefficient in cases of DG Integration guarantee the coordination between different distance relays in the microgrid. The infeed coefficient provides security and reliability for the performance of protection schemes in active networks and microgrids consist of multiple DG units and in the uncertainty of supply situations.

\section{Conclusion}

The continuous and frequent integration of DGs into the $\mathrm{DNs}$ is a widespread practice in existing networks nowadays. The fluctuating level of fault current levels due to the integration of such sources makes the performance of protection schemes based on current measurement unsuitable and inadequate. The employment of distance protective devices in complex distribution networks which rely on the value of impedance rather than the current measurement enhances the stability and safety of microgrid operation. Although the highlighted advantages, an adaptive scheme require a convenient communication infrastructure between various relays in the network. The penetration of DG units in the microgrid may affect, especially, the second and third phases of the distance relay scheme. This impact could cause nonselective tripping and miscoordination between primary and backup relay pairs. The utilization of adaptive approach with predefined values dampens the problems of DG integration on the backup stages in distance relaying scheme as well as in case of ground faults that are difficult to detect by conventional overcurrent schemes. The proposed arrangement ensures stability and selectivity between distance protective relays for optimum protection designs in future active networks.

\section{References}

Brahma, S. M., \& Girgis, A. A. (2004). Development of adaptive protection scheme for distribution systems with high penetration of distributed generation. IEEE Transactions on power delivery, 19(1), 56-63.

Che, L., Khodayar, M. E., \& Shahidehpour, M. (2014). Adaptive Protection System for Microgrids: Protection practices of a functional microgrid system. IEEE Electrification magazine, $2(1), 66-80$.
Coffele, F., Booth, C., \& Dyśko, A. (2015). An adaptive overcurrent protection scheme for distribution networks. IEEE Transactions on Power Delivery, 30(2), 561-568.

Deng, W., Pei, W., Shen, Z., Zhao, Z., \& Qu, H. (2015). Adaptive micro-grid operation based on IEC 61850. Energies, 8(5), 4455-4475. [22] El Naily, N., Saad, S. M., Hussein, T., \& Mohamed, F. A. (2017). Minimizing the impact of distributed generation of a weak distribution network with an artificial intelligence technique. Applied Solar Energy, 53(2), 109-122.

El Naily, N., Saad, S. M., Elsayed, R. E., Aomura, S. A., \& Mohamed, F. A. (2018, March). Planning \& application of distance relays coordination for IEC microgrid considering intermediate in-feed factor. In Renewable Energy Congress (IREC), 2018 9th International (pp. 1-6). IEEE.

Gers, J. M., \& Holmes, E. J. (2005). Protection of electricity distribution networks (Vol. 47). IET.

Hooshyar, A., \& Iravani, R. (2017). Microgrid protection. Proceedings of the IEEE, 105(7), 1332-1353.

Hosseini, S. A., Abyaneh, H. A., Sadeghi, S. H. H., Razavi, F., \& Nasiri, A. (2016). An overview of microgrid protection methods and the factors involved. Renewable and Sustainable Energy Reviews, 64, 174-186.

Hsieh, S. C., Chen, C. S., Tsai, C. T., Hsu, C. T., \& Lin, C. H. (2014). Adaptive relay setting for distribution systems considering operation scenarios of wind generators. IEEE Transactions on Industry Applications, 50(2), 1356-1363.

IEEE Standards Association. (2011). IEEE guide for design, operation, and integration of distributed resource island systems with electric power systems. IEEE std, 1547-4.

IEEE Standards Association. (2011). IEEE std 1547.4-2011, IEEE guide for design, operation, and integration of distributed resource island systems with electric power systems. New York: IEEE.

Kar, S. (2017). A comprehensive protection scheme for micro-grid using fuzzy rule base approach. Energy Systems, 8(3), 449464.

Kar, S., Jati, D., \& Samantaray, S. R. (2016, March). Overcurrent relay coordination for micro-grid with different operating conditions. In Power Systems (ICPS), 2016 IEEE 6th International Conference on (pp. 1-6). IEEE.

Kar, S., Samantaray, S. R., \& Zadeh, M. D. (2017). Data-mining model based intelligent differential microgrid protection scheme. IEEE Systems Journal, 11(2), 1161-1169.

Khandare, P., Deokar, S. A., \& Dixit, A. M. (2017, April). Advanced technique in micro grid protection for various fault by using numerical relay. In 2017 2nd International Conference for Convergence in Technology (I2CT) (pp. 803807). IEEE.

Lasseter, R. H. (2011). Smart distribution: Coupled microgrids. Proceedings of the IEEE, 99(6), 1074-1082.

Mahat, P., Chen, Z., Bak-Jensen, B., \& Bak, C. L. (2011). A Simple Adaptive Overcurrent Protection of Distribution Systems With Distributed Generation. IEEE Trans. Smart Grid, 2(3), 428-437.

Memon, A. A., \& Kauhaniemi, K. (2015). A critical review of AC Microgrid protection issues and available solutions. Electric Power Systems Research, 129, 23-31.

Moirangthem, J., Krishnanand, K. R., \& Saranjit, N. (2011, December). Optimal coordination of overcurrent relay using an enhanced discrete differential evolution algorithm in a distribution system with DG. In Energy, Automation, and Signal (ICEAS), 2011 International Conference on (pp. 1-6). IEEE.

Najy, W. K., Zeineldin, H. H., \& Woon, W. L. (2013). Optimal protection coordination for microgrids with grid-connected and islanded capability. IEEE Transactions on industrial electronics, 60(4), 1668-1677.

Neplan, A. G., \& Switzerland, B. C. P. NEPLAN 360 Overview.

Nikkhajoei, H., \& Lasseter, R. H. (2006). Microgrid fault protection based on symmetrical and differential current components. Power System Engineering Research Center, 71-74. 
Nikolaidis, V. C., Tsimtsios, A. M., \& Safigianni, A. S. (2018). Investigating Particularities of Infeed and Fault Resistance Effect on Distance Relays Protecting Radial Distribution Feeders With DG. IEEE Access, 6, 11301-11312.

Saad, S. M., El Naily, N., Elhaffar, A., El-Arroudi, K., \& Mohamed, F. A. (2017, March). Applying adaptive protection scheme to mitigate the impact of distributed generator on existing distribution network. In Renewable Energy Congress (IREC), 2017 8th International (pp. 1-6). IEEE.

Sharaf, H. M., Zeineldin, H. H., Ibrahim, D. K., \& Essam, E. L. (2015). A proposed coordination strategy for meshed distribution systems with DG considering user-defined characteristics of directional inverse time overcurrent relays. International Journal of Electrical Power \& Energy Systems, 65, 49-58.

Sinclair, A., Finney, D., Martin, D., \& Sharma, P. (2014). Distance protection in distribution systems: How it assists with integrating distributed resources. IEEE Transactions on Industry Applications, 50(3), 2186-2196.

Sortomme, E., Ren, J., \& Venkata, S. S. (2013, July). A differential zone protection scheme for microgrids. In Power and Energy Society General Meeting (PES), 2013 IEEE (pp. 1-5). IEEE.

Sortomme, Eric, S. S. Venkata, and Joydeep Mitra. (2010). Microgrid protection using communication-assisted digital relays. IEEE Transactions on Power Delivery 25, no. 4 (2010), 2789-2796.

TSIMTSIOS, A., \& NIKOLAIDIS, V. (2018). Application of Distance Protection in Mixed Overhead-Underground Distribution Feeders with Distributed Generation.

Zeineldin, H. H., El-Saadany, E. F., \& Salama, M. M. A. (2006, March). Distributed generation micro-grid operation: Control and protection. In Power Systems Conference: Advanced Metering, Protection, Control, Communication, and Distributed Resources, 2006. PS'06 (pp. 105-111). IEEE.

Zeineldin, H. H., Sharaf, H. M., Ibrahim, D. K., \& El-Zahab, E. E. D. A. (2015). Optimal Protection Coordination for Meshed Distribution Systems with DG Using Dual Setting Directional Over-Current Relays. IEEE Trans. Smart Grid, 6(1), 115-123. 